\title{
The Wnt antagonists DKK1 and SFRP1 are downregulated by promoter hypermethylation in systemic sclerosis
}

\author{
Clara Dees, ${ }^{1}$ Inga Schlottmann, ${ }^{1}$ Robin Funke, ${ }^{1}$ Alfiya Distler, ${ }^{1}$ Katrin Palumbo-Zerr, ${ }^{1}$ \\ Pawel Zerr, ${ }^{1}$ Neng-Yu Lin, ${ }^{1}$ Christian Beyer, ${ }^{1}$ Oliver Distler, ${ }^{2}$ Georg Schett, ${ }^{1}$ \\ Jörg H W Distler ${ }^{1}$
}

Handling editor Tore K Kvien

- Additional material is published online only. To view please visit the journal online (http://dx.doi.org/10.1136/ annrheumdis-2012-203194).

${ }^{1}$ Department of Internal Medicine III and Institute for Clinical Immunology, University of Erlangen-Nuremberg, Erlangen, Germany ${ }^{2}$ Center of Experimental Rheumatology and Zurich Center of Integrative Human Physiology, University Hospital Zurich, Zurich, Switzerland

Correspondence to Dr Jörg H W Distler,

Department of Internal Medicine 3 and Institute for Clinical Immunology, University of Erlangen-Nuremberg, Ulmenweg 18, Erlangen 91054, Germany; joerg.distler@uk-erlangen.de

Accepted 2 May 2013 Published Online First 22 May 2013
To cite: Dees $C$, Schlottmann I, Funke R, et al. Ann Rheum Dis 2014;73:1232-1239.

\section{ABSTRACT}

Objective Activated Wnt signalling with decreased expression of endogenous inhibitors has recently been characterised as a central pathomechanism in systemic sclerosis (SSc). Aberrant epigenetic modifications also contribute to the persistent activation of SSc fibroblasts. We investigated whether increased Wnt signalling and epigenetic changes in SSc are causally linked via promoter hypermethylation-induced silencing of Wnt antagonists.

Methods The methylation status of endogenous Wnt antagonists in leucocytes and fibroblasts was evaluated by methylation-specific PCR. 5-aza-2'-deoxycytidine was used to inhibit DNA methyltransferases (Dnmts) in cultured fibroblasts and in the mouse model of bleomycin-induced skin fibrosis. Activation of Wnt signalling was assessed by analysing Axin2 mRNA levels and by staining for $\beta$-catenin.

Results The promoters of DKK1 and SFRP1 were hypermethylated in fibroblasts and peripheral blood mononuclear cells of patients with SSc. Promoter hypermethylation resulted in impaired transcription and decreased expression of DKK1 and SFRP1 in SSC. Treatment of SSc fibroblasts or bleomycin-challenged mice with 5-aza prevented promoter methylation-induced silencing and increased the expression of both genes to normal levels. Reactivation of DKK1 and SFRP1 transcription by 5 -aza inhibited canonical Wnt signalling in vitro and in vivo and effectively ameliorated experimental fibrosis.

Conclusions We demonstrate that hypermethylation of the promoters of DKK1 and SFRP1 contributes to aberrant Wnt signalling in SSC and that Dnmt inhibition effectively reduces Wnt signalling. These data provide a novel link between epigenetic alterations and increased Wnt signalling in SSc and also have translational implications because Dnmt inhibitors are already approved for clinical use.

\section{INTRODUCTION}

Systemic sclerosis ( $\mathrm{SSc}$ ) is a connective tissue disease that affects the skin and various internal organs. The major hallmark is a progressive accumulation of extracellular matrix. ${ }^{1}$ The resulting tissue fibrosis commonly leads to organ failure and is a major cause of high morbidity and lethality in patients with SSc. The accumulation of extracellular matrix is caused by persistently activated fibroblasts. ${ }^{2}$ However, the molecular mechanisms of the aberrant activation of SSc fibroblasts are only partially understood.

Recent work has identified canonical Wnt signalling as one of the central profibrotic signalling pathways in SSc. ${ }^{3-10}$ When the tight balance between Wnt proteins and their endogenous antagonists is shifted towards Wnt protein, the $\beta$-catenin destruction complex, consisting of Axin, Adenomatosis Polyposis Coli and Glycogen Synthase Kinase 3 is inhibited and phosphorylation and subsequent degradation of $\beta$-catenin are prevented. $\beta$-Catenin accumulates in the cytoplasm and translocates to the nucleus where it binds to $T$ cell factor/lymphoid enhancer-binding factor (Tcf/ Lef) to induce the transcription of Wnt target genes such as Axin2. ${ }^{11}$ In SSc, canonical Wnt signalling is activated by overexpression of Wnt proteins and by downregulation of the endogenous Wnt antagonists. ${ }^{3-5} 10$ The activation of canonical Wnt signalling stimulates resident fibroblasts to differentiate into myofibroblasts and to release abundant amounts of collagen. Activation of canonical Wnt signalling either by overexpression of Wnt proteins or a stabilised form of $\beta$-catenin or by inhibition of Glycogen Synthase Kinase 3 rapidly induce fibrosis in mice, thereby highlighting the key role of Wnt signalling for fibroblast activation and tissue fibrosis in SSc. ${ }^{3-5} 10$

Epigenetic alterations have also been shown to play a key role in the pathogenesis of SSc. ${ }^{12-14}$ The best characterised epigenetic modification is DNA methylation. DNA methylation occurs at cytosine residues on position 5 of the pyrimidine ring within $\mathrm{CpG}$ dinucleotides of the promoters of target genes. ${ }^{15}$ The addition of methyl groups to $\mathrm{CpG}$ dinucleotides leads to restructuring of the chromatin packing of DNA and inhibits gene transcription by interference with the recruiting of transcriptional coactivators, thereby preventing transcription of the respective gene. ${ }^{16}$ DNA methylation is tightly controlled by different DNA methyltransferases (Dnmt1, Dnmt3a and Dnmt3b). These Dnmts are accessible for targeting by small molecule inhibitors, with two specific inhibitors already approved for clinical use. ${ }^{17}$

We investigated whether epigenetic alterations and increased Wnt signalling may be causally linked to each other in SSc. Hypermethylation of 
the promoters of endogenous Wnt antagonists have been described to activate Wnt signalling in various tumours and may correlate with prognosis. ${ }^{18}{ }^{23}$ Based on these observations in cancers, we hypothesised that promoter hypermethylation may contribute to the decrease of Wnt antagonists and the activation of Wnt signalling in SSc.

\section{MATERIALS AND METHODS}

\section{Patients and fibroblast cultures}

Fibroblast cultures were obtained from biopsies of lesional skin from patients with SSc $(n=25)$ and from healthy volunteers $(n=21)$ as described previously. ${ }^{24}{ }^{25}$ Blood samples were collected from 76 patients and 76 healthy volunteers. All patients with SSc fulfilled the criteria for SSc as suggested by LeRoy et $a l .{ }^{26}$ The characteristics of the patients are summarised in online supplementary tables $1 \mathrm{~A}$ and $1 \mathrm{~B}$.

\section{Prevention of bleomycin-induced dermal fibrosis}

For prevention of dermal fibrosis, 6-week-old pathogen-free male $\mathrm{DBA} / 2$ mice were injected with bleomycin for 3 weeks as described elsewhere. ${ }^{25} 27$ Mice receiving subcutaneous injections of $100 \mu \mathrm{l} 0.9 \% \mathrm{NaCl}$ served as controls. One group each of $\mathrm{NaCl}-$ or bleomycin-challenged mice was additionally treated with the Dnmt inhibitor and nucleoside analogue 5-aza- $2^{\prime}$-deoxycytidine (5-aza), which is incorporated into the DNA and blocks Dnmt activity by forming covalent bonds with the enzyme. ${ }^{28} 295$-Aza was applied by intraperitoneal injections every third day at a dose of $0.5 \mathrm{mg} / \mathrm{kg}$ whereas the control groups received injections of the solvent $2 \%$ dimethyl sulfoxide (DMSO).

\section{Incubation with inhibitors of Dnmts}

Dermal fibroblasts were incubated with 5-aza (Sigma-Aldrich, Steinheim, Germany) at a concentration of $10 \mu \mathrm{M}$ for $24 \mathrm{~h}$. This concentration is pharmacologically relevant and can be achieved in vivo. ${ }^{30} 31$ Fibroblasts incubated with the same volumes of the solvent DMSO were used as controls.

\section{Isolation of DNA}

Genomic DNA was isolated from fibroblasts and leucocytes from patients with SSc and healthy volunteers using the DNeasy Blood and Tissue kit (Qiagen, Düsseldorf, Germany) according to the instructions of the manufacturer.

\section{Methylation-specific PCR}

For bisulfite modification of DNA, $20 \mu \mathrm{l}$ of genomic DNA were processed using the EpiTect Bisulfite kit (Qiagen). The sequences of the primer pairs used for methylation- and unmethylation-specific PCR are summarised in online supplementary table 2 . The reaction mixture contained $50 \mathrm{ng}$ bisulfite converted DNA in a final volume of $50 \mu \mathrm{l}$. Each product was loaded onto a $2 \%$ agarose gel and visualised under ultraviolet illumination. Each band was quantified using ImageJ software (V.1.42).

\section{Quantitative real-time PCR}

Total RNA was isolated with the NucleoSpin RNA II extraction system (Macherey-Nagel, Düren, Germany) and reverse transcribed into cDNA as described elsewhere. ${ }^{32} 33$ Gene expression was quantified by real-time PCR using the MxPro 3005P QPCR System (Agilent Technologies, Santa Clara, California, USA). Specific primer pairs for each gene were designed with the Primer 3 software (see online supplementary table 3 ). Measurement of $\beta$-actin levels was used to normalise for the amounts of loaded cDNA. Non-specific signals caused by contamination with genomic DNA or by formation of primer dimers were excluded with samples without enzyme in the reverse transcription (non-RT controls), samples without cDNA (no template controls) and dissociation curve analysis. Differences were calculated with the threshold cycle $(\mathrm{Ct})$ and the comparative $\mathrm{Ct}$ method for relative quantification.

\section{Immunocytochemistry}

Cultured fibroblasts from patients with SSc and healthy controls were fixed with $4 \%$ methanol-free paraformaldehyde and permeabilised with $0.25 \%$ Triton-X100. Staining was performed with rabbit anti- $\beta$-catenin (Abcam, Cambridge, UK) or mouse anti- $\alpha$ SMA (Sigma-Aldrich) antibodies. Alexa Fluor 594-conjugated anti-rabbit or Alexa Fluor 488-conjugated anti-mouse antibodies (Invitrogen) served as secondary antibodies. Counterstaining of nuclei was performed with 4',6-diamidino-2-phenylindole (DAPI; Santa Cruz Biotechnology, Santa Cruz, California, USA). Fluorescence intensity was analysed using ImageJ software (V.1.42).

\section{Western blot analysis}

Protein lysates from cultured fibroblasts were obtained by resuspension of the cell pellet in $1 \times$ Laemmli buffer. Lysates were loaded onto a $10 \%$ SDS polyacrylamide gel and blotted to polyvinylidene difluoride membranes. The membranes were incubated with anti-DKK1 (Epitomics, Burlingame, California, USA) and anti-SFRP1 (Abcam). Equal loading of proteins was confirmed by incubation with anti- $\beta$-actin (Sigma-Aldrich). Horseradisch peroxidase-conjugated anti-rabbit or anti-mouse antibodies (Dako Cytomation, Glostrup, Denmark) were used as secondary antibodies. Quantification was performed with Image J software (V.1.42).

\section{Immunohistochemistry}

Formalin-fixed, paraffin-embedded or fresh frozen (for SFRP1) skin sections were stained with anti- $\beta$-catenin, anti-SFRP1 (both Abcam), anti-DKK1 (R\&D Systems, Minneapolis, Minnesota, USA) or anti- $\alpha$ SMA (Sigma-Aldrich). Concentration-matched and species-specific immunoglobulins (Vector Laboratories, Burlingame, California, USA) served as control antibodies. Secondary antibodies were labelled with Alexa Fluor 594, Alexa Fluor 488 (both Invitrogen) or horseradish peroxidase (Dako Cytomation). Nuclei were counterstained with DAPI. To evaluate accumulation of $\beta$-catenin in fibroblasts, skin sections were doublestained for $\beta$-catenin and the fibroblast marker vimentin (Abcam). Staining intensity for DKK1 and SFRP1 in keratinocytes, fibroblasts and vessels of human skin sections was evaluated by semiquantitative analyses with a score ranging from 0 to 3 (0: no staining, 1: weak staining, 2: moderate staining, 3: strong staining).

\section{Statistical analysis}

All data are presented as median (IQR) and differences between groups were tested by the non-parametric Mann-Whitney U test for their statistical significance. A p value of $<0.05$ was considered statistically significant.

\section{RESULTS}

\section{Promoters of DKK1 and SFRP1 are hypermethylated in SSc}

We first analysed the methylation status of the endogenous Wnt antagonists DKK1, DKK2, DKK3, SFRP1 and WIF1 in peripheral blood mononuclear cells (PBMCs), which had been shown to be regulated by DNA methylation in cancer. ${ }^{34}{ }^{39}$ Analyses by methylation-specific PCR showed significantly increased methylation for DKK1 and SFRP1 in PBMCs from patients 
A

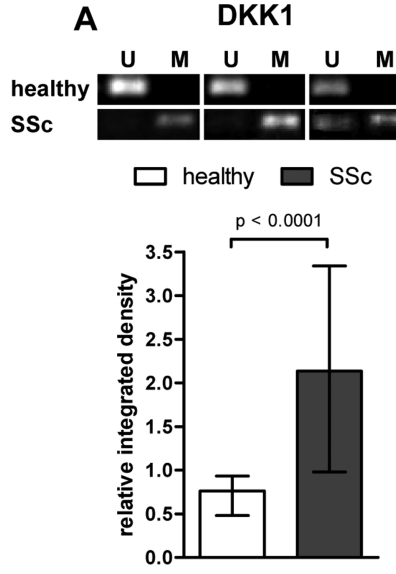

SFRP1
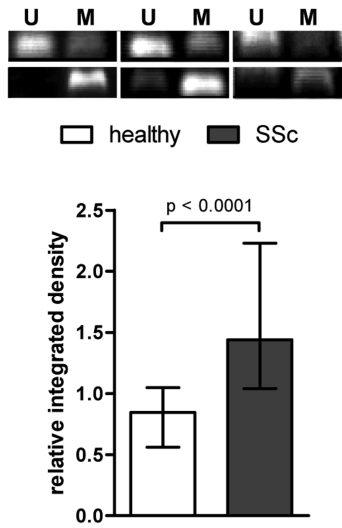

B
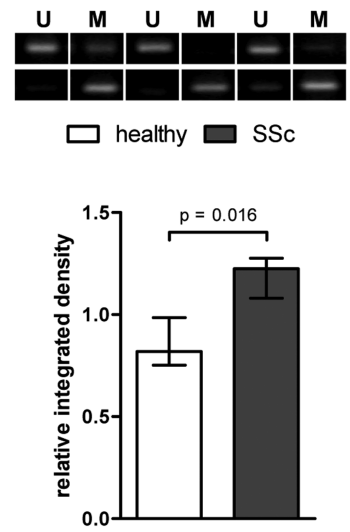

SFRP1
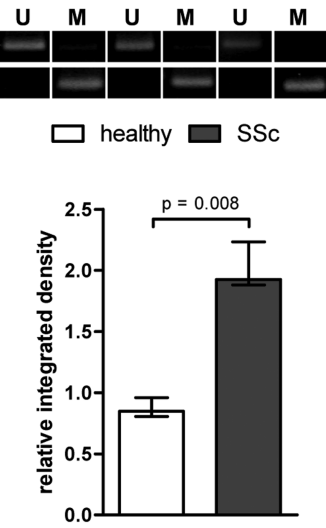

Figure 1 DKK1 and SFRP1 are hypermethylated in peripheral blood mononuclear cells (PBMCs) and fibroblasts from patients with systemic sclerosis (SSc). The promoters of DKK1 and SFRP1 were hypermethylated in (A) PBMCs ( $n=76$ each) and (B) fibroblasts $(n=5$ each) from patients with SSC as analysed by methylation-specific PCR. The ratios of methylation-specific PCR products $(\mathrm{M})$ to unmethylated PCR products $(\mathrm{U})$ were increased in patients with SSC compared with healthy individuals. Representative images of agarose gels and quantification of the relative ratios of methylation-specific PCR products (M) to unmethylated PCR products $(\mathrm{U})$ are shown.

with SSc compared with healthy individuals (figure 1A). We also observed a trend towards hypermethylation for WIF1, whereas no differences were detected for DKK2 and DKK3. We next analysed whether DKK1 and SFRP1 are also hypermethylated in SSc fibroblasts as the key effector cells of fibrosis. Analyses of the promoters of DKK1 and SFRP1 by methylation-specific PCR demonstrated prominent hypermethylation in SSc fibroblasts, with increased ratios of methylated PCR products to
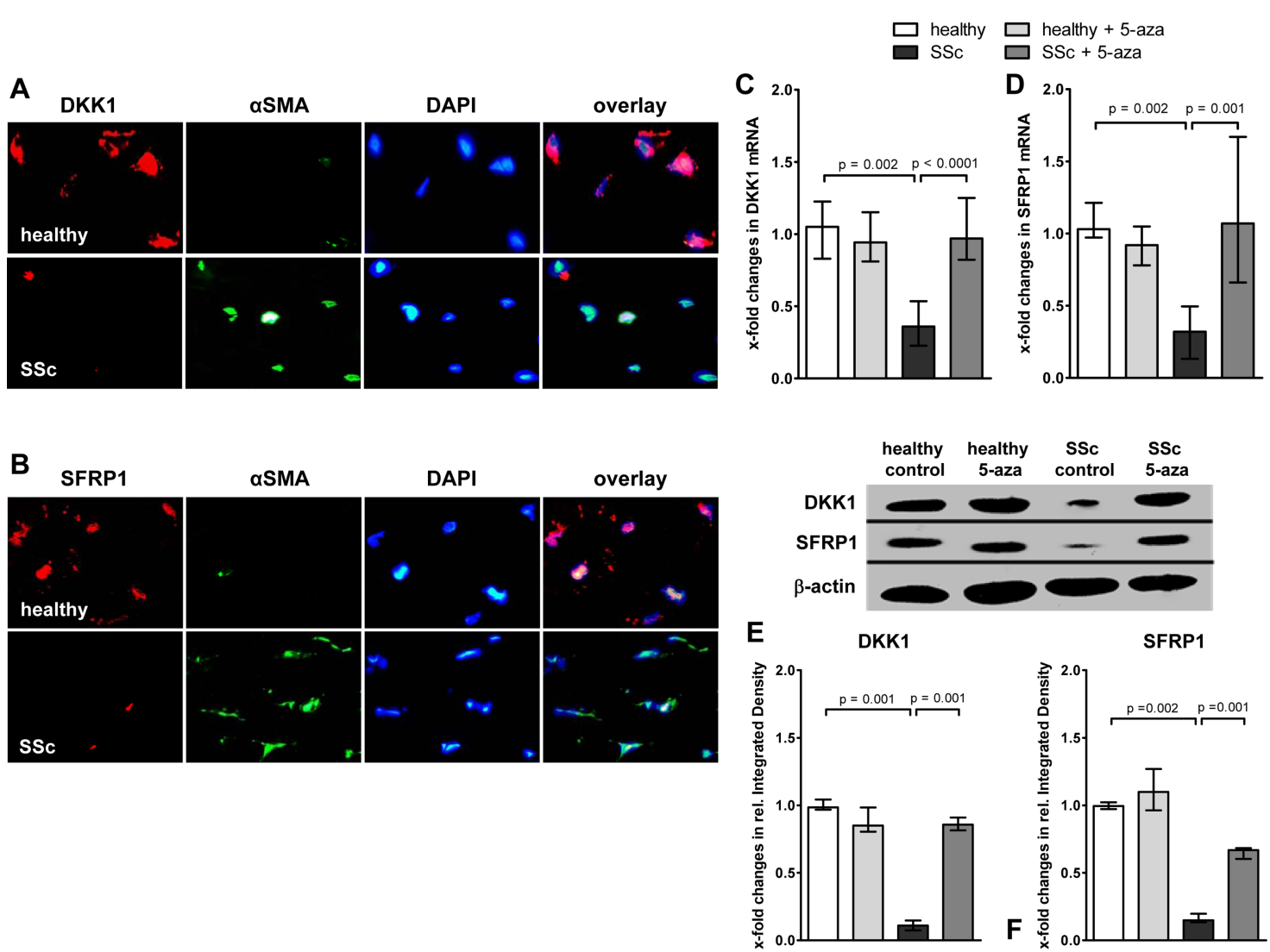

Figure 2 The expression of the Wnt antagonists DKK1 and SFRP1 is repressed in systemic sclerosis (SSc). Immunohistochemical co-staining for (A) DKK1 and (B) SFRP1 and $\alpha$ SMA in skin sections from patients with SSc $(n=8)$ and healthy controls $(n=7)$. Representative images $(\times 1000$ magnification) demonstrate downregulation of DKK1 and SFRP1 in myofibroblasts in skin from patients with SSc. (C, D) mRNA and (E, F) protein levels of DKK1 and SFRP1 were strongly reduced in cultured fibroblasts from patients with SSc ( $n=9$ for mRNA, $n=3$ for protein) compared with fibroblasts from healthy individuals ( $n=6$ for $m R N A, n=3$ for protein). Incubation of SSc fibroblasts with 5 -aza normalised the expression of both genes to control levels (C-F). 
unmethylated PCR products compared with fibroblasts from age- and sex-matched healthy volunteers (figure $1 \mathrm{~B}$ ). The relative integrated density (methylated/unmethylated PCR products) increased in SSc fibroblasts by $49 \%$ for DKK1 $(p=0.016)$ and by $127 \%$ for SFRP1 ( $p=0.008)$ compared with fibroblasts from healthy controls (figure 1B). We observed a trend towards increased methylation of both promoters in patients with active disease (EULAR Systemic Sclerosis Activity Score $\geq 3$ ) and diffuse cutaneous SSc but the differences did not reach statistical significance $(p=0.09$ and $p=0.10)$. No correlations with other manifestations such as disease duration or vascular manifestations were observed.

\section{Expression of DKK1 and SFRP1 is decreased in SSC}

We next aimed to confirm that the hypermethylation of the promoters of DKK1 and SFRP1 leads to decreased expression of both Wnt antagonists. Intense staining for DKK1 was observed in fibroblasts and vascular cells of healthy individuals, whereas there was only weak expression in keratinocytes. In contrast, the expression of DKK1 was strongly decreased in fibroblasts of patients with SSc $(p=0.0007)$ with only scattered fibroblasts stained for DKK1 (see online supplementary figure 1A). Similar to DKK1, the expression of SFRP1 was also reduced in SSc. In healthy individuals, staining for SFRP1 was not restricted to fibroblasts and vessels in the dermis but was also observed in epidermal keratinocytes. The expression of SFRP1 was strongly reduced in dermal fibroblasts of patients with SSc $(\mathrm{p}<0.0001)$, in addition to significant decreases of SFRP1 in keratinocytes and vascular structures $(p<0.0001$ for both; see online supplementary figure 1B). Moreover, co-stainings of DKK1 or SFRP1 and $\alpha$ SMA demonstrated prominently decreased expression of DKK1 and SFRP1 in $\alpha$ SMA-positive myofibroblasts in skin from patients with SSc (figure 2A,B).

We then analysed the expression of DKK1 and SFRP1 in cultured fibroblasts. The mRNA levels of DKK1 and SFRP1 were both decreased in SSc fibroblasts with decreases of $66 \%$ and $72 \%$, respectively, compared with fibroblasts from healthy individuals ( $p=0.002$ for both; figure 2C,D). To confirm that these decreases are indeed due to promoter hypermethylation, we incubated SSc fibroblasts with the DNA methyltransferase inhibitor 5-aza. Inhibition of Dnmts significantly increased the mRNA levels of DKK1 and SFRP1 in SSc fibroblasts to levels comparable to those of fibroblasts from healthy individuals (figure 2C,D). Similar results were obtained on the protein level with significantly reduced expression in SSc fibroblasts $(p=0.001$ and $p=0.002$; figure 2E,F). Incubation with 5-aza strongly induced protein expression of both DKK1 and SFRP1 $(\mathrm{p}=0.001$ for both; figure $2 \mathrm{E}, \mathrm{F})$. In contrast, 5-aza had only minor effects on the expression of DKK1 and SFRP1 in healthy fibroblasts (figure 2C-F).

Next we analysed the expression of DKK1 and SFRP1 and the effect of Dnmt inhibitors in experimental fibrosis. The
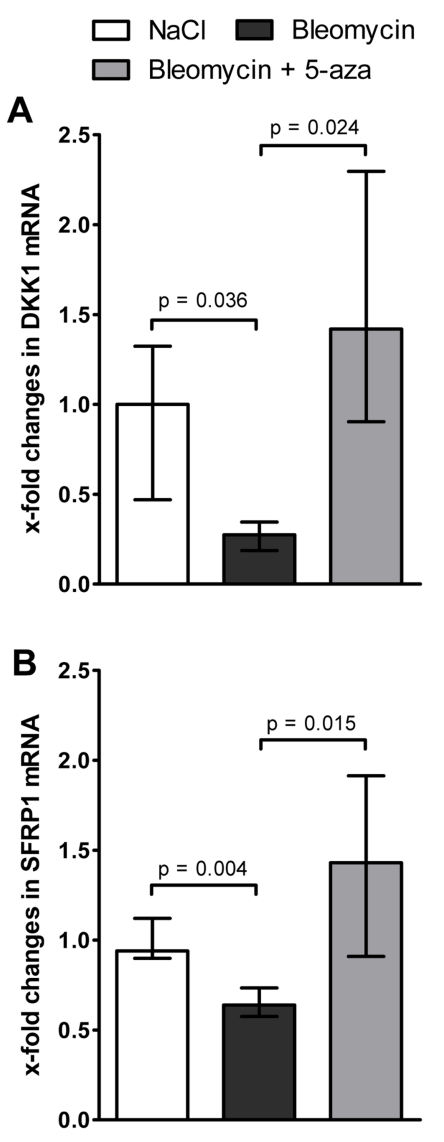

\section{C}

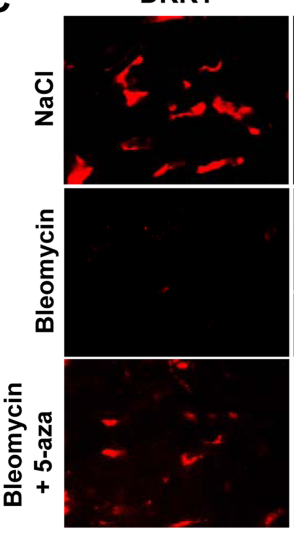

D

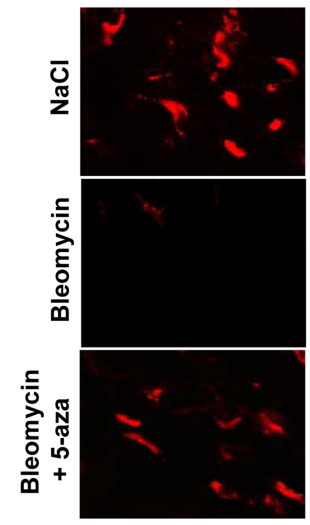

aSMA

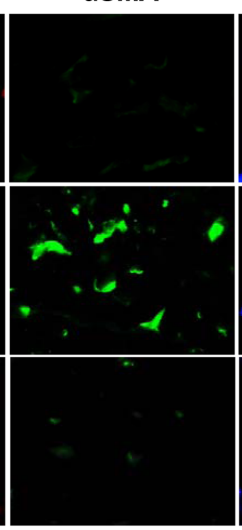

aSMA
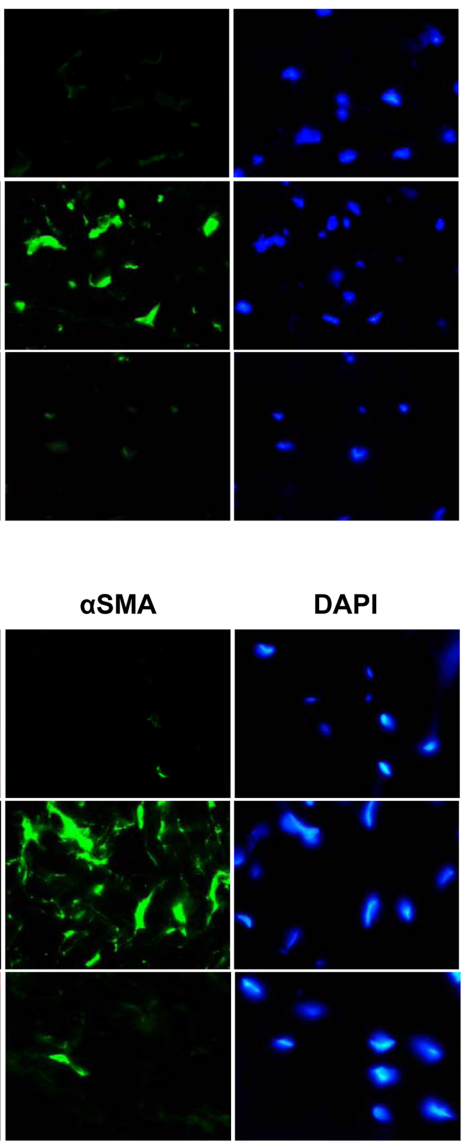

DAPI

DAPI

overlay
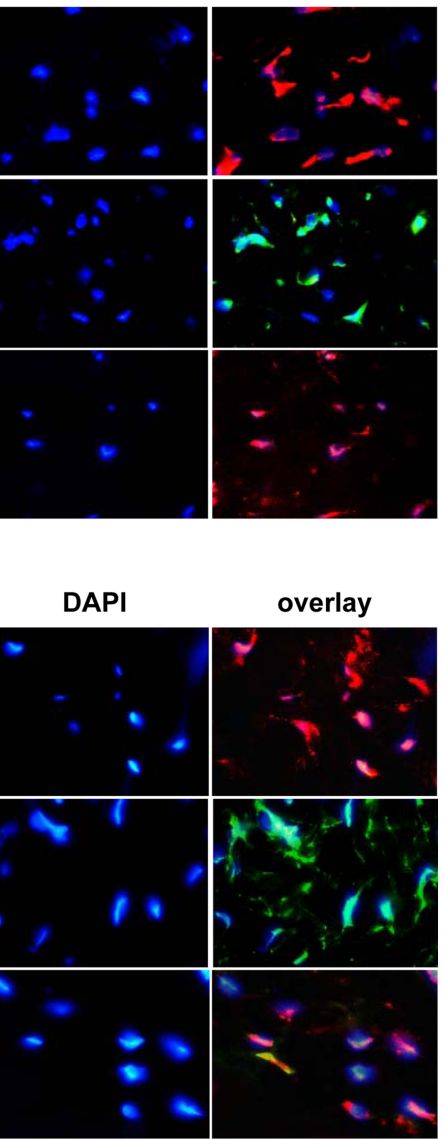

Figure 3 DKK1 and SFRP1 are downregulated by promoter methylation in bleomycin-induced dermal fibrosis. The mRNA levels of (A) DKK1 and (B) SFRP1 were strongly decreased in the skin of bleomycin-challenged mice ( $n=5$ for $\mathrm{NaCl}, \mathrm{n}=6$ for bleomycin). Treatment with 5 -aza completely prevented the repressive effects of bleomycin on DKK1 and SFRP1 mRNA $(n=8)$. Inhibition of DNA methyltransferases also prevented the downregulation of (C) DKK1 and (D) SFRP1 protein in fibroblasts in the skin of bleomycin-challenged mice as shown by immunohistochemical co-staining for the myofibroblast marker $\alpha$ SMA and DKK1 or SFRP1 ( $n=3$ for each group). 

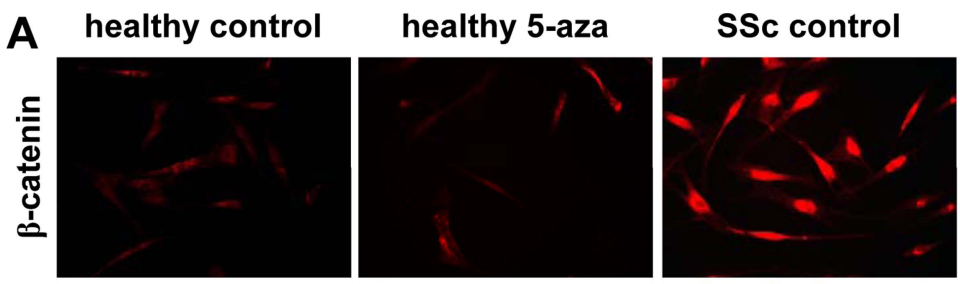

SSc + 5-aza
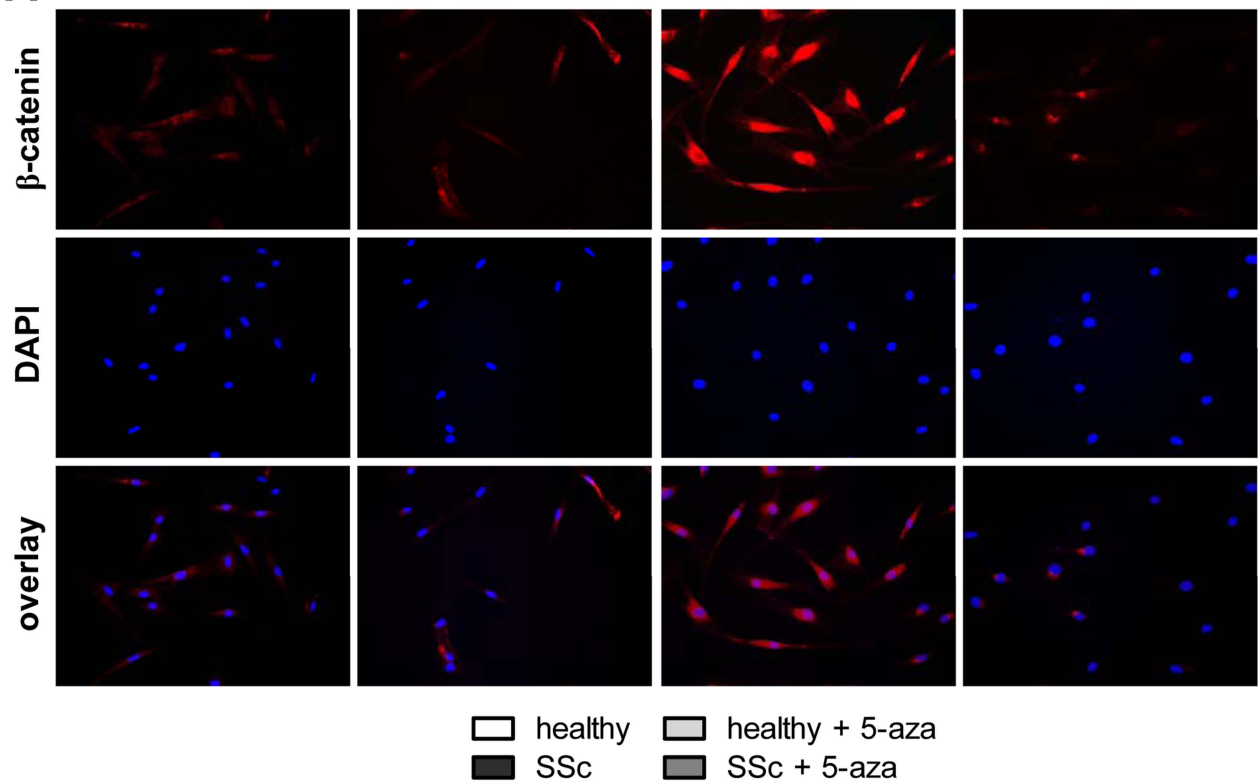

healthy + 5-aza

SSc + 5-aza

B

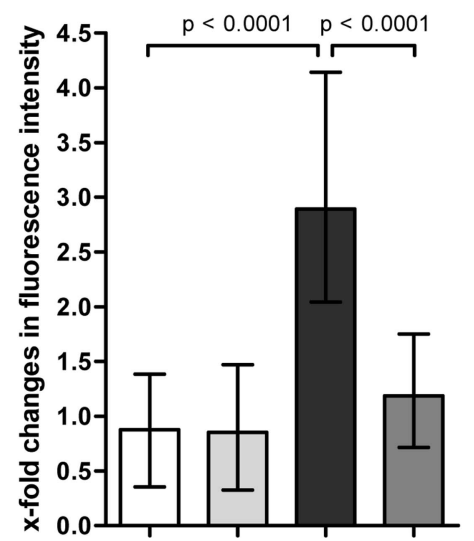

C

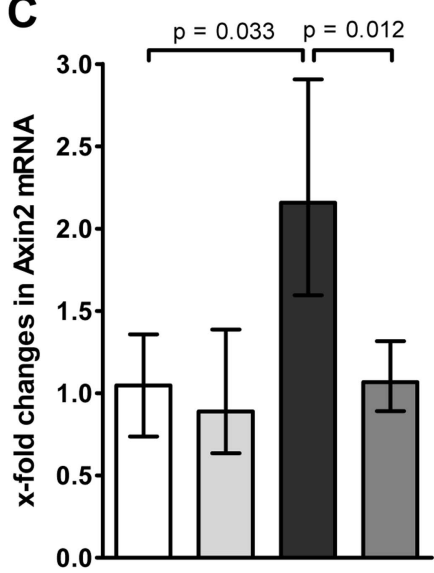

Figure 4 Inhibition of DNA methyltransferases reduces Wnt signalling in systemic sclerosis (SSc) fibroblasts. Incubation of SSc fibroblasts with 5 -aza reduced the nuclear levels of $\beta$-catenin as analysed by immunocytochemical staining ( $n=3$ each) (A, B) and decreased the expression of the Wnt target gene Axin2 ( $n=4$ each) (C). Representative images are shown at $\times 200$ magnification.

mRNA levels of DKK1 and SFRP1 were significantly reduced in the skin of mice upon challenge with bleomycin. However, treatment with 5-aza prevented the bleomycin-induced decreases of DKK1 and SFRP1 (figure 3A,B). The levels of DKK1 and SFRP1 in bleomycin-challenged mice treated with 5-aza were comparable to those of non-fibrotic control mice. Similar results were obtained on the protein level with strong decreases in DKK1 and SFRP1 expression in $\alpha$ SMA-positive myofibroblasts in bleomycin-challenged mice and normal levels in mice cotreated with 5-aza (figure 3C,D).

Together, these data demonstrate that the expression of DKK1 and SFRP1 is silenced by promoter hypermethylation in experimental fibrosis and in SSc and that their expression can be reactivated by Dnmt inhibitors.

\section{Inhibition of Dnmts reduces canonical Wnt signalling}

We next determined whether treatment with Dnmt inhibitors and subsequent reactivation of the expression of DKK1 and SFRP1 is sufficient to inhibit canonical Wnt signalling. Indeed, incubation with 5-aza reduced the nuclear accumulation of $\beta$-catenin, the central integrator of canonical Wnt signalling, in SSc fibroblasts by $60 \%(\mathrm{p}<0.0001$; figure $4 \mathrm{~A}, \mathrm{~B})$. Moreover, the levels of the $\mathrm{Wnt} / \beta$-catenin target gene Axin2 were also decreased by $93 \%(p=0.012)$ in SSc fibroblasts upon incubation with 5-aza (figure 4C), demonstrating that Dnmt inhibitors can effectively decrease canonical Wnt signalling in SSc fibroblasts. Again, only minor changes on $\beta$-catenin levels and Axin2 mRNA upon incubation with 5-aza were observed in fibroblasts from healthy subjects (figure 4A-C).

Inhibition of Dnmts also reduced canonical Wnt signalling in bleomycin-induced fibrosis. Treatment with 5 -aza effectively prevented the nuclear accumulation of $\beta$-catenin in $\alpha$ SMA-positive myofibroblasts in bleomycin-injected skin (figure 5A) and the number of $\beta$-catenin-positive fibroblasts identified by co-staining with vimentin were significantly decreased (figure 5B). Moreover, the mRNA levels of Axin2 were significantly lower in bleomycin-challenged mice treated with 5-aza as compared with sham-treated bleomycin-challenged mice (figure 5C). Thus, treatment with Dnmts effectively inhibits canonical Wnt signalling in SSc fibroblasts and in experimental fibrosis. 
A
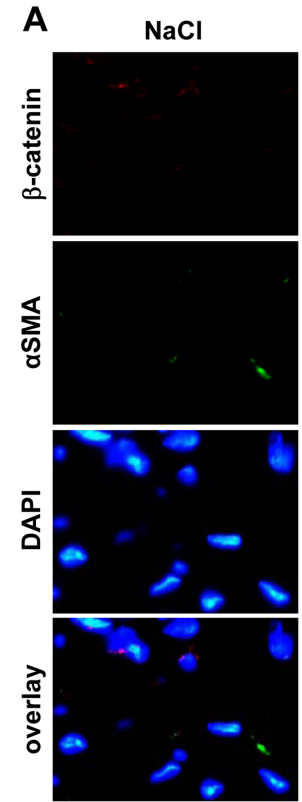

Bleomycin
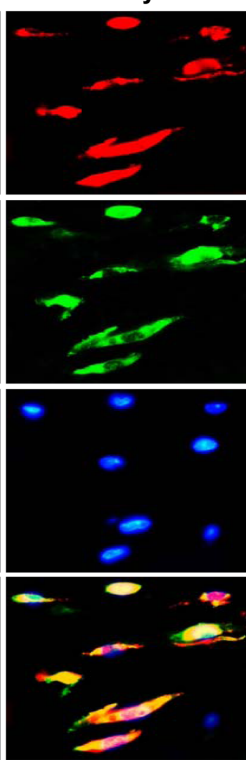

Bleomycin + 5-aza
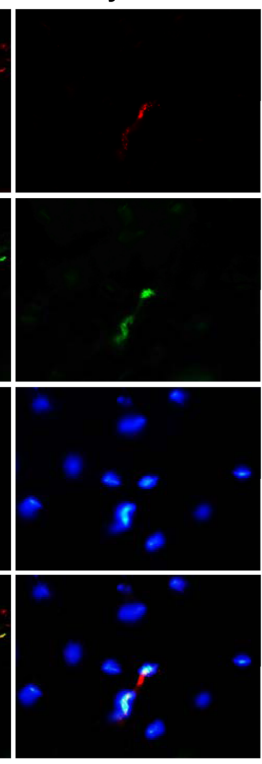

B

$\mathrm{NaCl} \square$ Bleomycin

Bleomycin + 5-aza
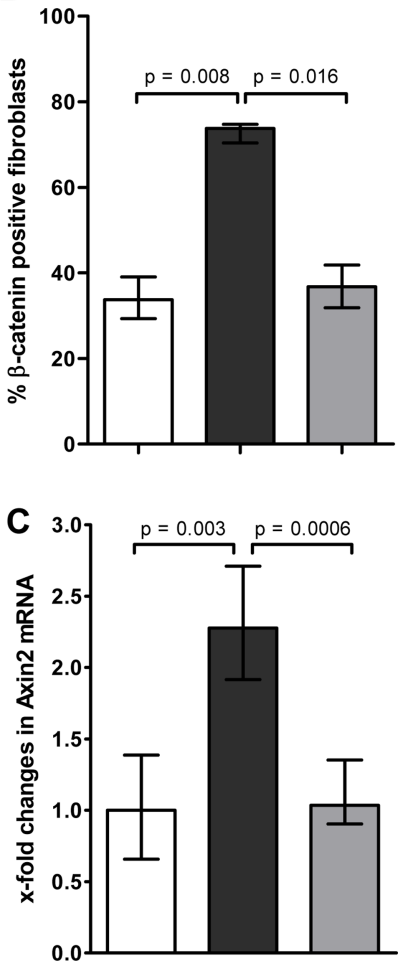

Figure 5 Treatment with 5-aza prevents bleomycin-induced activation of canonical Wnt signalling. (A) Representative images of skin sections triple-stained for $\beta$-catenin, DAPI and the myofibroblast marker $\alpha$ SMA are shown at $\times 1000$ magnification. Treatment of bleomycin-challenged mice with 5 -aza (B) reduced the number of vimentin-positive fibroblasts with nuclear staining for $\beta$-catenin to the levels of non-fibrotic control mice $(n=5$ for each group) and (C) prevented the bleomycin-induced upregulation of Axin2 mRNA ( $n=5$ for $\mathrm{NaCl}$ and bleomycin, $n=8$ for bleomycin +5 -aza).

A

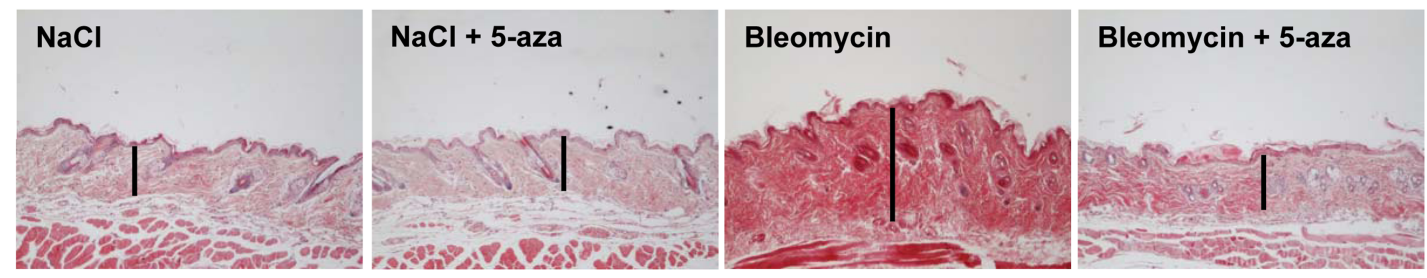

$\mathrm{NaCl}+5$-aza

Bleomycin

Bleomycin + 5-aza

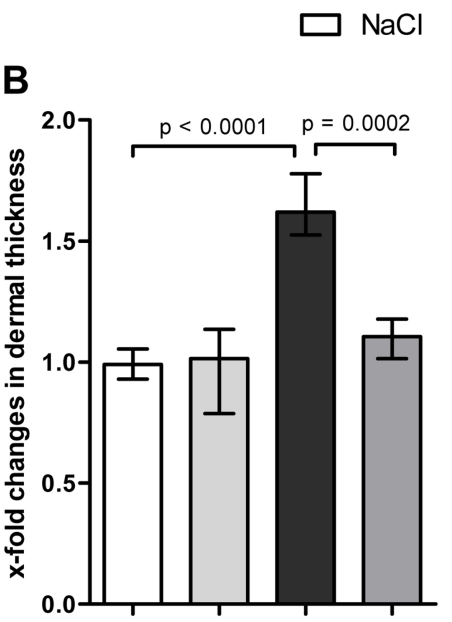

B

C

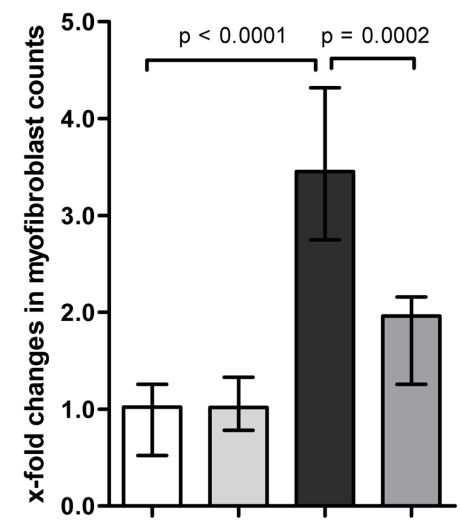

D

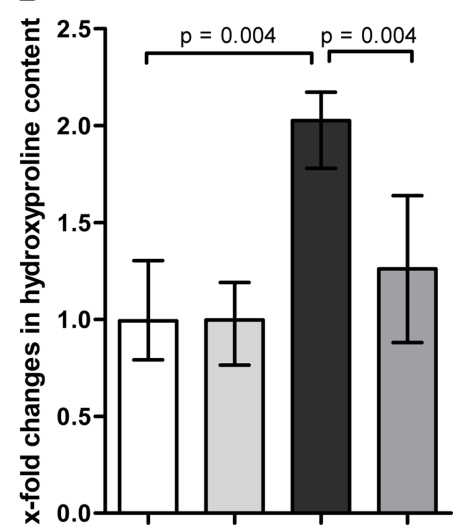

Figure 6 Inhibition of DNA methyltransferases prevents bleomycin-induced dermal fibrosis. (A) Representative H\&E stained tissue sections are shown at $\times 100$ magnification. Vertical bars indicate dermal thickness. Treatment with 5 -aza at a dose of $0.5 \mathrm{mg} / \mathrm{kg}$ every third day prevented the increase in (B) dermal thickness, (C) myofibroblast counts and (D) hydroxyproline content upon challenge with bleomycin ( $\mathrm{n}=13 \mathrm{for} \mathrm{NaCl}, \mathrm{n}=6 \mathrm{for}$ $\mathrm{NaCl}+5$-aza, $\mathrm{n}=12$ for bleomycin, $\mathrm{n}=8$ for bleomycin+5-aza). 


\section{Treatment with Dnmt inhibitors ameliorates experimental fibrosis}

We next evaluated whether the inhibition of Wnt signalling upon inhibition of Dnmts translates into antifibrotic effects. Subcutaneous injections of bleomycin induced prominent skin fibrosis with dermal thickening, differentiation of resting fibroblasts into myofibroblasts and increased hydroxyproline content (figure 6A-D). Treatment with 5-aza effectively reduced bleomycin-induced fibrosis. Dermal thickening, myofibroblast differentiation and increases in hydroxyproline content were reduced by $84 \%, 61 \%$ and $75 \%$, respectively, compared with sham-treated mice challenged with bleomycin $(p=0.0002$, $p=0.0002$ and $p=0.004$, respectively; figure $6 B-D)$. Signs of adverse effects like changes in the texture of the fur or in body weight were not observed upon treatment with 5 -aza (see online supplementary figure 2).

\section{DISCUSSION}

In the present study we unravel a first link between epigenetic alterations and aberrant Wnt signalling in SSc. We demonstrate that the promoters of the endogenous Wnt antagonists DKK1 and SFRP1 are hypermethylated in SSc, leading to reduced expression of both Wnt antagonists in SSc. These findings are of particular interest because decreased expression of Wnt antagonists is thought to be a major cause of increased Wnt signalling in SSc. ${ }^{3}$ DNA hypermethylation may thus contribute to the pathological activation of canonical Wnt in SSc. ${ }^{14}{ }^{40}$ Indeed, inhibition of DNA methylation completely restored the expression of DKK1 and SFRP1 and reduced the activation of canonical Wnt signalling in cultured SSc fibroblasts and in experimental skin fibrosis to the levels of normal fibroblasts and non-fibrotic mice, respectively. These findings highlight perturbed DNA methylation as a novel molecular mechanism contributing to the pathological activation of Wnt signalling in SSc.

In addition to direct inhibitory effects on fibroblasts, Dnmt inhibitors may also reduce fibroblast activation indirectly by modulating $\mathrm{T}$ cell activation. Incubation with 5-azacytidine (5-azaC) induces a shift from Th2 to Th1 responses in cultured $\mathrm{T}$ cells with decreased release of interleukin- 4 and slightly increased release of interleukin- $6 .{ }^{41}$ As release of Th2 cytokines contributes to the aberrant activation of fibroblasts in SSc, inhibition of Th2 responses may contribute to the inhibitory effects of Dnmt inhibitors in SSc and fibrotic diseases.

These observations may also have direct translational implications. Considering (1) the potent profibrotic effects of canonical Wnt signalling, (2) the reversibility of DNA methylation, (3) the availability of potent Dnmt inhibitors and (4) the potent reduction of canonical Wnt signalling by inhibition of Dnmts, Dnmt inhibitors may be an interesting novel approach to inhibit fibroblast activation by targeting canonical Wnt signalling. The canonical Wnt pathway has long been considered as 'undruggable'. Although several promising targets within the canonical Wnt pathway have been identified during recent years, no inhibitor of those targets has yet been developed beyond phase 1 or phase 2 clinical trials. ${ }^{42-44}$ In contrast, two Dnmt inhibitors, 5-aza-2'-deoxycytidine (Decitabine) and 5-azacytidine (Vidaza), have been approved for clinical use. ${ }^{17}$ Of note, Dnmt inhibitors are generally well tolerated. The only adverse effect that occurred in more than $5 \%$ of treated patients in clinical trials was myelosuppression, whereas other severe adverse effects were rare. ${ }^{45} 46$ Thus, Dnmt inhibitors would be directly available for clinical trials in SSc, there is considerable experience with Dnmt inhibitors from other diseases and their use may not be limited by toxicity.

However, although the good tolerability of Dnmt inhibitors has been proved in thousands of patients with myelodysplastic syndromes or leukaemia, careful monitoring for unexpected adverse events in other indications is still warranted, particularly due to the mechanism of action of Dnmt inhibitors. Despite the potent increases in the expression of the Wnt antagonists DKK1 and SFRP1 by treatment with Dnmt inhibitors, targeting Dnmts will not selectively modulate canonical Wnt signalling but also affect other genes and signalling cascades that are regulated by promoter methylation. Modulation of other genes probably contributes to the antifibrotic effects of Dnmt inhibitors. Even though the DNA methylome of SSc fibroblasts has not yet been defined, FLI1 and SOCS3 have already been identified as antifibrotic genes hypermethylated in SSc fibroblasts. ${ }^{14} 40$ Thus, Dnmt inhibitors, like all epigenetic drugs, are not selectively modulating one antifibrotic pathway but rather several pathways, thereby shifting gene expression from a profibrotic to an antifibrotic profile. ${ }^{47}$ Although modulation of multiple targets may theoretically increase the risk for adverse events, it may also increase the antifibrotic potential. Simultaneous targeting of multiple profibrotic pathways may exert additive antifibrotic effects. This hypothesis is supported by preclinical studies and also by the encouraging results obtained with the multi-tyrosine kinase inhibitor nintedanib (BIBF 1120) in a large randomised controlled phase 2 trial in patients with idiopathic pulmonary fibrosis. $^{48} 49$

In summary, we have identified a novel link between DNA methylation and aberrant Wnt signalling in SSc. We have shown that the endogenous Wnt antagonists DKK1 and SFRP1 are silenced by promoter hypermethylation in SSc. Inhibition of Dnmts reactivated the expression of DKK1 and SFRP1 and effectively ameliorated experimental fibrosis by inhibiting canonical Wnt signalling. Dnmt inhibitors may therefore be an interesting novel approach to target Wnt signalling in SSc and other fibrotic diseases.

Acknowledgements We thank Katja Dreißigacker, Stefan Fritz and Verena Wäsch for excellent technical assistance.

Contributors Design of the study: $C D, J H W D$. Acquisition of data: $C D, I S, R F, A D$, $K P-Z, P Z, N-Y L, C B$. Interpretation of data: CD, IS, RF, AD, KP-Z, PZ, N-YL, CB, OD, GS, JHWD. Manuscript preparation: CD, OD, GS, JHWD.

Funding This study was funded by grants $J 29$ and A40 from the Interdisciplinary Center of Clinical Research (IZKF) in Erlangen, grants from the German Research Foundation (Grants DI 1537/1-1, DI 1537/2-1, DI 1537/4-1, DI 1537/5-1, BE 5191/1-1, AK 144/1-1 and SCHE 1583/7-1) and a Career Support Award of Medicine from the Ernst Jung Foundation. The funders had no influence on the design of the study or the interpretation of the results.

Competing interests OD has consultancy relationships and/or has received research funding from Actelion, Pfizer, Ergonex, BMS, Sanofi-Aventis, United BioSource Corporation, medac, Biovitrium, Boehringer Ingelheim, Novartis, $4 \mathrm{D}$ Science and Active Biotec in the area of potential treatments of scleroderma. JHWD has consultancy relationships and/or has received research funding from Actelion, Pfizer, Ergonex, BMS, Celgene, Bayer Pharma, Boehringer Ingelheim, JB Therapeutics, Sanofi-Aventis, Novartis, Array Biopharma and Active Biotec in the area of potential treatments of scleroderma and is stock owner of 4D Science GmbH.

Patient consent Obtained.

Ethics approval Medical Faculty of the University of Erlangen-Nuremberg.

Provenance and peer review Not commissioned; externally peer reviewed.

\section{REFERENCES}

1 Gabrielli A, Avvedimento EV, Krieg T. Scleroderma. N Engl J Med 2009:360:1989-2003.

2 Varga J, Abraham D. Systemic sclerosis: a prototypic multisystem fibrotic disorder. J Clin Invest 2007;117:557-67. 
3 Akhmetshina A, Palumbo K, Dees C, et al. Activation of canonical Wnt signalling is required for TGF-beta-mediated fibrosis. Nat Commun 2012;3:735.

4 Bergmann C, Akhmetshina A, Dees C, et al. Inhibition of glycogen synthase kinase 3 beta induces dermal fibrosis by activation of the canonical Wnt pathway. Ann Rheum Dis 2011;70:2191-8.

5 Beyer C, Schramm A, Akhmetshina A, et al. beta-catenin is a central mediator of pro-fibrotic Wnt signaling in systemic sclerosis. Ann Rheum Dis 2012;71:761-7.

6 Colwell AS, Krummel TM, Longaker MT, et al. Wnt-4 expression is increased in fibroblasts after TGF-beta1 stimulation and during fetal and postnatal wound repair. Plast Reconstr Surg 2006;117:2297-301.

7 Konigshoff M, Kramer M, Balsara N, et al. WNT1-inducible signaling protein-1 mediates pulmonary fibrosis in mice and is upregulated in humans with idiopathic pulmonary fibrosis. J Clin Invest 2009;119:772-87.

8 Surendran K, McCaul SP, Simon TC. A role for Wnt-4 in renal fibrosis. Am J Physiol Renal Physiol 2002;282:F431-441.

9 Wei J, Fang F, Lam AP, et al. Wnt/beta-catenin signaling is hyperactivated in systemic sclerosis and induces Smad-dependent fibrotic responses in mesenchymal cells. Arthritis Rheum 2012;64:2734-45.

10 Wei J, Melichian D, Komura K, et al. Canonical Wnt signaling induces skin fibrosis and subcutaneous lipoatrophy: a novel mouse model for scleroderma? Arthritis Rheum 2011;63:1707-17.

11 Nusse R. Wnt signaling in disease and in development. Cell Res 2005;15:28-32.

12 Huber LC, Distler JH, Moritz F, et al. Trichostatin A prevents the accumulation of extracellular matrix in a mouse model of bleomycin-induced skin fibrosis. Arthritis Rheum 2007:56:2755-64.

13 Maurer B, Stanczyk J, Jungel A, et al. MicroRNA-29, a key regulator of collagen expression in systemic sclerosis. Arthritis Rheum 2010;62:1733-43.

14 Wang Y, Fan PS, Kahaleh B. Association between enhanced type I collagen expression and epigenetic repression of the FLI1 gene in scleroderma fibroblasts. Arthritis Rheum 2006;54:2271-9.

15 Esteller M. Epigenetics in cancer. N Engl J Med 2008;358:1148-59.

16 Klose RJ, Bird AP. Genomic DNA methylation: the mark and its mediators. Trends Biochem Sci 2006;31:89-97.

17 Oki Y, Issa JP. Review: recent clinical trials in epigenetic therapy. Rev Recent Clin Trials 2006;1:169-82.

18 Atschekzei F, Hennenlotter J, Janisch S, et al. SFRP1 CpG island methylation locus is associated with renal cell cancer susceptibility and disease recurrence. Epigenetics 2012;7:447-57.

19 Gao Z, Xu Z, Hung MS, et al. Procaine and procainamide inhibit the Wnt canonical pathway by promoter demethylation of WIF-1 in lung cancer cells. Oncol Rep 2009:22:1479-84.

20 Kawakami K, Yamamura S, Hirata $\mathrm{H}$, et al. Secreted frizzled-related protein-5 is epigenetically downregulated and functions as a tumor suppressor in kidney cancer. Int I Cancer 2011;128:541-50.

21 Lo PK, Mehrotra J, D'Costa A, et al. Epigenetic suppression of secreted frizzled related protein 1 (SFRP1) expression in human breast cancer. Cancer Biol Ther 2006:5:281-6.

22 Wang $\mathrm{X}$, Wang $\mathrm{H}, \mathrm{Bu}$ R, et al. Methylation and aberrant expression of the Wnt antagonist secreted Frizzled-related protein 1 in bladder cancer. Oncol Lett 2012:4:334-8.

23 Zhu J, Wang Y, Duan J, et al. DNA Methylation status of Wnt antagonist SFRP5 can predict the response to the EGFR-tyrosine kinase inhibitor therapy in non-small cell lung cancer. J Exp Clin Cancer Res 2012;31:80.

24 Akhmetshina A, Dees C, Pileckyte $M$, et al. Dual inhibition of $c$-abl and PDGF receptor signaling by dasatinib and nilotinib for the treatment of dermal fibrosis. FASEB J 2008:22:2214-22.

25 Distler JH, Jungel A, Huber LC, et al. Imatinib mesylate reduces production of extracellular matrix and prevents development of experimental dermal fibrosis. Arthritis Rheum 2007:56:311-22.

26 LeRoy EC, Medsger TA Jr. Criteria for the classification of early systemic sclerosis. J Rheumatol 2001;28:1573-6.
27 Lakos G, Takagawa S, Chen SJ, et al. Targeted disruption of TGF-beta/Smad3 signaling modulates skin fibrosis in a mouse model of scleroderma. Am J Pathol 2004:165:203-17.

28 Santi DV, Garrett CE, Barr PJ. On the mechanism of inhibition of DNA-cytosine methyltransferases by cytosine analogs. Cell 1983;33:9-10.

29 Santi DV, Norment A, Garrett CE. Covalent bond formation between a DNA-cytosine methyltransferase and DNA containing 5-azacytosine. Proc Natl Acad SCi USA 1984;81:6993-7.

30 Eramo A, Pallini R, Lotti F, et al. Inhibition of DNA methylation sensitizes glioblastoma for tumor necrosis factor-related apoptosis-inducing ligand-mediated destruction. Cancer Res 2005;65:11469-77.

31 McCabe MT, Low JA, Daignault S, et al. Inhibition of DNA methyltransferase activity prevents tumorigenesis in a mouse model of prostate cancer. Cancer Res 2006;66:385-92.

32 Distler JH, Jungel A, Huber LC, et al. The induction of matrix metalloproteinase and cytokine expression in synovial fibroblasts stimulated with immune cell microparticles. Proc Natl Acad Sci USA 2005;102:2892-7.

33 Jungel A, Distler 0 , Schulze-Horsel $U$, et al. Microparticles stimulate the synthesis of prostaglandin $E(2)$ via induction of cyclooxygenase 2 and microsomal prostaglandin E synthase 1. Arthritis Rheum 2007;56:3564-74.

34 Aguilera O, Fraga MF, Ballestar E, et al. Epigenetic inactivation of the Wnt antagonist DICKKOPF-1 (DKK-1) gene in human colorectal cancer. Oncogene 2006;25:4116-21.

35 Delmas AL, Riggs BM, Pardo CE, et al. WIF1 is a frequent target for epigenetic silencing in squamous cell carcinoma of the cervix. Carcinogenesis 2011;32:1625-33.

36 Kansara M, Tsang M, Kodjabachian L, et al. Wnt inhibitory factor 1 is epigenetically silenced in human osteosarcoma, and targeted disruption accelerates osteosarcomagenesis in mice. J Clin Invest 2009;119:837-51.

37 Suzuki H, Toyota M, Carraway H, et al. Frequent epigenetic inactivation of Wnt antagonist genes in breast cancer. $\mathrm{Br} J$ Cancer 2008;98:1147-56.

38 Yu J, Tao Q, Cheng YY, et al. Promoter methylation of the Wnt/beta-catenin signaling antagonist Dkk-3 is associated with poor survival in gastric cancer. Cancer 2009;115:49-60.

39 Zhu J, Zhang S, Gu L, et al. Epigenetic silencing of DKK2 and Wnt signal pathway components in human ovarian carcinoma. Carcinogenesis 2012;33:2334-43.

40 Dees C, Akhmetshina A, Busch N, et al. TGFb stimulates promoter hypermethylation and subsequent silencing of the anti-fibrotic gene socs3. Arthritis Rheum 2009;60: S474.

41 Yung RL, Quddus J, Chrisp CE, et al. Mechanism of drug-induced lupus. I. Cloned Th2 cells modified with DNA methylation inhibitors in vitro cause autoimmunity in vivo. J Immunol 1995;154:3025-35.

42 Beyer C, Dees C, Distler JH. Morphogen pathways as molecular targets for the treatment of fibrosis in systemic sclerosis. Arch Dermatol Res 2013;305:1-8.

43 Beyer $\mathrm{C}$, Reichert $\mathrm{H}$, Akan $\mathrm{H}$, et al. Blockade of canonical Wnt signaling ameliorates experimental dermal fibrosis. Ann Rheum Dis 2013;72:1255-8.

44 Distler $A$, Deloch L, Huang J, et al. Inactivation of tankyrases reduces experimental fibrosis by inhibiting canonical Wnt signalling. Ann Rheum Dis 2013:72:1575-80.

45 Kantarjian H, Issa JP, Rosenfeld CS, et al. Decitabine improves patient outcomes in myelodysplastic syndromes: results of a phase III randomized study. Cancer 2006;106:1794-803.

46 Kantarjian H, Oki Y, Garcia-Manero G, et al. Results of a randomized study of 3 schedules of low-dose decitabine in higher-risk myelodysplastic syndrome and chronic myelomonocytic leukemia. Blood 2007;109:52-7.

47 Jungel A, Distler JH, Gay S, et al. Epigenetic modifications: novel therapeutic strategies for systemic sclerosis? Expert Rev Clin Immunol 2011;7:475-80.

48 Downey GP. Resolving the scar of pulmonary fibrosis. N Engl J Med 2011:365:1140-1.

49 Richeldi L, Costabel U, Selman M, et al. Efficacy of a tyrosine kinase inhibitor in idiopathic pulmonary fibrosis. N Engl J Med 2011;365:1079-87. 


\section{ARD The Wnt antagonists DKK1 and SFRP1 are} downregulated by promoter hypermethylation in systemic sclerosis

Clara Dees, Inga Schlottmann, Robin Funke, Alfiya Distler, Katrin Palumbo-Zerr, Pawel Zerr, Neng-Yu Lin, Christian Beyer, Oliver Distler, Georg Schett and Jörg H W Distler

Ann Rheum Dis 2014 73: 1232-1239 originally published online May 22, 2013

doi: 10.1136/annrheumdis-2012-203194

Updated information and services can be found at:

http://ard.bmj.com/content/73/6/1232

These include:

Supplementary Material

References

Email alerting service
Supplementary material can be found at:

http://ard.bmj.com/content/suppl/2013/05/22/annrheumdis-2012-2031 94.DC1.html

This article cites 47 articles, 13 of which you can access for free at: http://ard.bmj.com/content/73/6/1232\#BIBL

Receive free email alerts when new articles cite this article. Sign up in the box at the top right corner of the online article.

Topic
Collections

Articles on similar topics can be found in the following collections

\section{Notes}

To request permissions go to:

http://group.bmj.com/group/rights-licensing/permissions

To order reprints go to:

http://journals.bmj.com/cgi/reprintform

To subscribe to BMJ go to:

http://group.bmj.com/subscribe/ 